\title{
ANALISIS SOAL-SOAL OLIMPIADE SAINS NASIONAL(OSN) SMA/MA BIDANG KIMIA TAHUN 2012 DAN 2013 BERDASARKAN DIMENSI PROSES KOGNITIF DANPENGETAHUAN
}

\author{
Tita Sunggarani $^{1}$, Euis Nursa'adah $^{1}$, Yunita $^{1}$
}

${ }^{1}$ Program Studi Pendidikan Kimia Fakultas Tarbiyah dan Keguruan UIN Sunan Gunung Djati Bandung

Email: sunggaraniFz@gmail.com

\begin{abstract}
Abstrak : Ilmu kimia sebagai ilmu yang berdasarkan pada penelitian (induktif), yang seharusnya mampu menyajikan soal yang menantang dan tersebar dalam enam level kognitif, hanya saja kondisi sebenarnya soal-soal kimia masih dibuat tradisional dengan berada pada level kognitif rendah. Soal olimpiade sebagai ajang kompetisi nasional siswa-siswa berprestasi di Indonesia pun belum diketahui level kognitif yang terkandung di dalamnya. Maka tujuan penelitian ini yakni, mendeskripsikan komposisi penyebaran soal terhadap tabel Taksonomi Bloom revisi, mendeskripsikan perbandingan soal OSN dan IChO (International Chemistry Olympiad) pada materi yang sama, dan memetakan soal-soal tersebut terhadap standar kompetensi dan kompetensi dasar SMA/MA. Hasil analisis menunjukkan bahwa pada tahun 2012 tersebar pada prosedural-mengaplikasikan dan konseptual-memahami. Pada tahun 2013 tersebar pada dimensi prosedural-mengaplikasikan dan faktual-memahami. Berdasarkan konten materi dalam satu soal $I C h O$ menuntut siswa dapat menemukan keterkaitan suatu materi dengan materi lainnya guna menyelesaikan soal tersebut sedangkan OSN tidak, tetapi keduanya memiliki dimensi pengetahuan dan dimensi proses kognitif yang tidak terlalu berbeda yakni pada lingkup prosedural-mengaplikasikan dan prosedural-menganalisis. Hasil pemetaan terhadap SKKD SMA/MA menunjukkan sebesar setengah dari jumlah ksesluruhan soal dapat dipetakan. Adanya analisis ini diharapkan menjadi masukan bagi guru untuk memberikan penguatan konsep kimia pada pembelajaran, agar siswa mampu mengerjakan berbagai macam soal, salah satunya soal OSN. Penelitian ini masih terbatas pada tahun 2012 dan 2013, sehingga dapat dikembangkan analisis untuk tahun-tahun lainnya.
\end{abstract}

Kata kunci: : Analisis, Taksonomi Bloom revisi, Dimensi Pengetahuan, Dimensi Proses Kognitif

\begin{abstract}
Chemistry as a science that is based on research (inductive), which is supposed to be able to present a challenging problem and scattered in six cognitive levels, it's just that the actual conditions of chemical problems are still made traditionally with low cognitive level. Olympics as a matter of national competition top students in Indonesia is not yet known cognitive level contained therein. So the purpose of this study, describing the composition of matter of the spread of the revised Bloom's Taxonomy tables, describing the comparison about OSN and IChO (International Chemistry Olympiad) on the same material, and to map these problems to the standards of competence and basic competences SMA/MA. The analysis showed that in 2012 spread over-apply procedural and conceptual understanding. In 2013 spread to the dimension-apply procedural and factual-understand. Based on the content of the material in a matter of IChO requires students to be able to find a material relationship with the other materials in order to resolve these problems while OSN does not, but both have dimensions of knowledge and cognitive process dimensions are not too different from that in the scope of procedural-procedural-applying and analyzing. The results of the mapping of the SK-KD SMA / MA shows only half the number of ksesluruhan matter can be mapped. The existence of this analysis are expected to be the input for the teacher to provide reinforcement in learning chemistry concepts, so that students are able to do a variety of problems, one of which is a matter of OSN. This study was limited in 2012 and 2013, so that the analysis can be developed for other years.
\end{abstract}

Keywords : Analysis, revised Bloom's Taxonomy, Knowledge Dimension, The Cognitive Process Dimension

\section{PENDAHULUAN}

Ilmu kimia merupakan ilmu yang dikembangkan berdasarkan penelitian (induktif), ilmu yang dapat menjabarkan fenomena-fenomena alam dan penjelasannya berhubungan dengan stuktur, sifat, komposisi, dinamika, energi, dan lainnya [1]. Dijelaskan oleh Atjenon [2], soalsoal yang diujikan khususnya pada materi kimia harusnya bersifat menantang dan mampu memisahkan siswa-siswa kedalam suatu kelompok tinggi atau rendah, sehingga 
sebaiknya soal mampu tersebar pada enam jenjang dimensi proses kognitif. Tetapi pada kenyataannya, di lapangan dunia pendidikan kimia kebanyakan soal berada pada kelompok LOCS (Lower-Order Cognitive Skills) atau kelompok rendah [3].

Penelitian yang telah dilakukan oleh Satrisman [4] menunjukkan soal level ujian nasional kimia pada tahun 2013 menempati presentasi terbanyak pada kelompok kognitif rendah, sedangkan ujian nasional di Finland persentasi terbanyak ditempati oleh level kognitif tinggi [5]. Penelitian lain di bidang soal olimpiade rumpun IPA seperti IPhO (International Physic Olympad) menunjukkan kebanyak soal berada pada perhitungan matematik yang berhubungan dengan pengetahuhan prosedural [6]. Penelitian lainnya seperti pada soal matematika PISA (Programme for International Student Assessment) menunjukkan pemecahan soal yang tidak familiar perlunya penalaran dan berhubungan dengan pengetahuan konseptual juga pengetahuan prosedural yang menuntut siswa berpikir dengan fleksibel, memikirkan jawaban dari setiap langkah dan tidak bergantung pada pemikiran awal saja [7].

Sebagai salah satu program penyaringan siswa yang akan dikutsertakan dalam kompetisi internasional, maka soal-soal yang diujikan dalam Olimpiade Sains Nasional, menjadi point yang penting, mengingat level soal secara nasional (Ujian Nasional) yang dibuat oleh Indonesia seringnya berada pada level kognitif kelompok rendah. Selain itu, dalam OSN ini pada setiap tahunnya tidak dicantumkan nama dari pembuat soal, juga tidak terdapatnya situs resmi yang bisa mengakses segala hal mengenai soal olimpiade tersebut, maka perlunya analisis terhadap soal-soal yang disajikan dalam olimpiade sains nasional ini. Pengelompokkan soal terhadap kognitif tinggi dan rendah dapat ditunjukkan pada analisis Taksonomi Bloom revisi [5], mengingat Taksonomi ini satu-satunya yang digunakan di Indonesia dan memilliki tingkat kepsefisikan yang baik dengan adanya dimensi proses kognitif dan pengetahuan.
Tujuan Berdasarkan beberapa hasil tersebut, penelitian ini bertujuan menganalisis soal-soal OSN (Olimpiade Sains Nasional) bidang kimia berdasarkan Taksonomi Bloom revisi, mendeskripsikan perbandingannya dengan soal IChO (Intermational Chemistry Olympiad, dan mengelompokkan soal terhadap SK-KD SMA/MA.

\section{TINJAUANTEORITIS}

Berdasarkan delapan jenis konsep kimia [8], beberapa topik soal-soal olimpide dapat dikelompokkan kedalamnya. Stoikiometri termasuk ke dalam jenis konsep berdasarkan prinsip karena mengandung pemahaman mengenai konsep mol, juga dapat mengandung konsep yang menyatakan ukuran atribut karena mengandung konsep seperti molaritas. Senyawa organik termasuk ke dalam konsep berdasarkan abstrak contoh konkrit. Konsep kesetimbangan kimia merupakan jenis konsep prinsip dan konsep menyatakan simbolik. Termodinamika merupakan jenis konsep prinsip, tetapi mengandung pula jenis konsep yang menyatakan simbolik. Asam-basa termasuk ke dalam konsep abstrak contoh konkrit, karena di dalamnya terkandung konsep mengenai kuat lemahnya suatu asam yang tidak terlihat secara langsung mengenai disosiasinya tetapi contohnya nyata. Kimia inti dan radiokimia dapat dikelompokkan ke dalam jenis konsep menyatakan abstrak yang di dalamnya terkadung konsep seperti penembakan unsur oleh unsur lain yang tidak dapat dilihat secara langsung, selain itu juga mengandung konsep yang menyatakan simbolik karena mengandung rumusan perhitungan kimia seperti waktu paruh dan lainnya.

Pada tahun 2001, Anderson dan Krathwohl telah melakukan revisi pada Taksonomi Bloom yang telah sekian lama digunakan di dunia pendidikan [9]. Hasil revisi ini adanya dua dimensi untuk menjelaskan suatu tujuan instruksional atau indikator, yakni dimensi proses kognitif sebagai kata kerja dan dimensi pengetahuan sebagai kata benda.

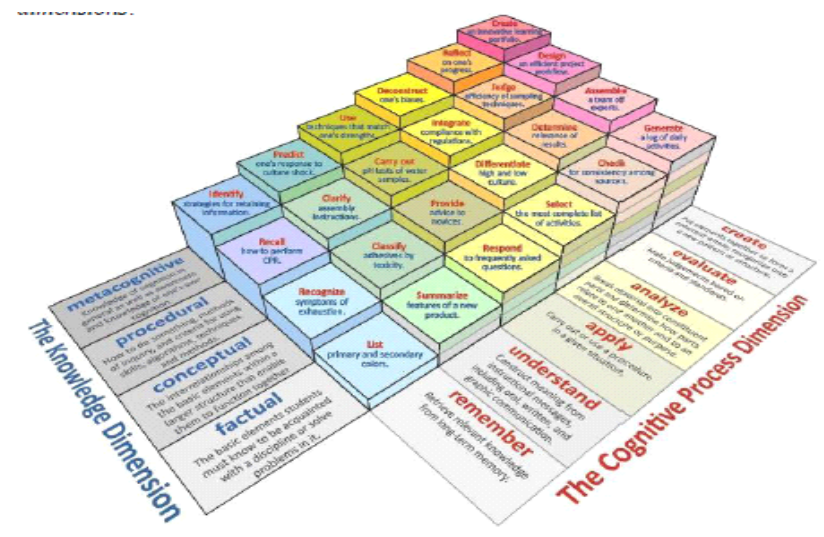

Gambar.1 Kombinasi dimensi pengetahuan dan dimensi proses kognitif [10] 
Dimensi proses kognitif terdiri dari enam jenjang, yakni mengingat, memahami, mengaplikasikan, menganalisis, mengevaluasi dan mencipta. Aplikasi dari Taksonomi Bloom revisi pada bidang kimia dijelaskan oleh Kratwohl [11]. Dimensi pengetahuan faktual ialah pengetahuan mengenai terminologi, contoh dalam studi kimia seperti simbol kimia, nama ilmuwan kimia, dll. Pengetahuan Konseptual adalah pengetahuan mengenai prinsip suatu teori berkenaan dengan generalisasi, contohnya teori atom atau prinsip Le Chatelier.

Pengetahun prosedural ialah teknik, metode, kemampuan penggunaan prosedur yang tepat, algoritma, contoh dalam studi kimia seperti kemampuan dalam praktikum, penggunan perhitungan matematik dalam kasus kimia dan lain-lain. Pengetahuan metakognitif yakni pengetahuan tentang kognisi keadaan seseorang dalam menyelesaikan masalah, biasanya pengetahuan ini akan lebih nampak dalam kemampuan psikomotor.

Tabel.1 menunjukkan kompleksitas meningkatkat dari kiri ke kanan pada dimensi kognitif, dan pada dimensi pengetahuan menunjukkan dimulai dengan pengetahuan konkrit (factual) hingga abstrak (metacognitive) [5].

\section{METODEPENELITIAN}

Soal yang dianalisis pada tahun 2012 berjumlah 33 soal uraian dan pada tahun 2013 berjumlah 44 soal uraian dengan penyajian wacana pada setiap pokok soal. Penelitian ini merupakan deskriptif kualitatif dengan jenis analisis konten. Metode ini dimaksudkan untuk mengetahui konten dimensi proses kognitif dan pengetahuan yang terdapat pada soal. Teknik yang dilakukan yakni, melakukan penyelesaian tahapan soal kemudian menganalisis dan mengkategorikannya terhadap kedua dimensi tersebut. Analisis juga dilakukan pada penyajian soal berhubungan dengan konten baik wacana soal. Hasil analisis di validasi oleh lima dosen ahli pada materi yang berkaitan dengan soal. Hasil validasi dihitung menggunakan CVR (Rasio Validitas Konten) dan CVI (Indeks Validitas Konten).

\section{HASIL PENELITIANDAN PEMBAHASAN}

Hasil analisis menunjukkan bahwa sebagian besar dari soal-soal OSN tahun 2012 dan 2013 sebanyak 77 soal terdapat pada dimensi proses kognitif mengaplikasikan dan dimensi pengetahuan prosedural. Soal ini terdiri dari beberapa materi kimia diantaranya, stoikiometri, kinetika reaksi, kesetimbangan kimia, senyawa organik, termodinamika, senyawa koordinasi/kompleks, kimia inti, dan reaksi redoks. Hasil validasi yang dilakukan oleh lima validator menunjukkan semua komponen memiliki nilai CVR dari rentang 0,6-0,99 dan niai CVI memiliki rentang dari 0,86-0,99.

Pada Taksonomi Bloom revisi dikenal adanya tabel Taksonomi (gabungan dari dimensi proses kognitif dan pengetahuan) yang berfungsi untuk menentukkan susunan indikator. Hasil penyebaran soal pada tahun 2012 disajikan pada tabel berikut.

Tabel 1. Taksonomi Bloom Revisi menurut Anderson dan Krathwohl [9]

\begin{tabular}{|c|c|c|c|c|c|c|}
\hline \multirow{2}{*}{$\begin{array}{l}\text { THE KNOWLEDGE } \\
\text { DIMENSION }\end{array}$} & \multicolumn{6}{|c|}{ THE COGNITIVE PROCESS DIMENSION } \\
\hline & $\begin{array}{l}1 . \\
\text { Remember }\end{array}$ & \begin{tabular}{|l}
2. \\
Understand
\end{tabular} & $\begin{array}{l}3 . \\
\text { Apply }\end{array}$ & $\begin{array}{l}4 . \\
\text { Analyse }\end{array}$ & $\begin{array}{l}\mathbf{5 .} \\
\text { Evaluate }\end{array}$ & $\begin{array}{l}6 . \\
\text { Create }\end{array}$ \\
\hline \multicolumn{7}{|l|}{ A. Factual knowledge } \\
\hline \multicolumn{7}{|l|}{ B. Conceptual knowledge } \\
\hline \multicolumn{7}{|l|}{ C. Procedural knowledge } \\
\hline D. Metacognitive knowledge & & & & & & \\
\hline
\end{tabular}

Tabel.2 Penyebaran soal Tahun 2012 dan 2013 pada tabel Taksonomi

\begin{tabular}{|c|c|c|c|c|c|c|c|c|c|c|c|c|c|}
\hline \multirow{3}{*}{ Tahun } & \multirow{3}{*}{$\begin{array}{c}\text { Dimensi } \\
\text { Pengetahuan }\end{array}$} & \multicolumn{12}{|c|}{ Dimensi Proses Kognitif } \\
\hline & & \multicolumn{2}{|c|}{$\begin{array}{l}\text { Meng- } \\
\text { ingat }\end{array}$} & \multicolumn{2}{|c|}{$\begin{array}{c}\text { Me- } \\
\text { mahami }\end{array}$} & \multicolumn{2}{|c|}{$\begin{array}{c}\text { Meng- } \\
\text { aplikasikan }\end{array}$} & \multicolumn{2}{|c|}{$\begin{array}{l}\text { Meng- } \\
\text { analisis, }\end{array}$} & \multicolumn{2}{|c|}{$\begin{array}{l}\text { Meng- } \\
\text { evaluasi }\end{array}$} & \multicolumn{2}{|c|}{ Mencipta } \\
\hline & & $\Sigma$ & $\%$ & $\Sigma$ & $\%$ & $\Sigma$ & $\%$ & $\Sigma$ & $\%$ & $\Sigma$ & $\%$ & $\Sigma$ & $\%$ \\
\hline \multirow{4}{*}{2012} & Faktual & - & - & - & - & - & - & - & - & - & - & - & - \\
\hline & Konseptual & - & - & 3 & $\begin{array}{l}9,1 \\
\%\end{array}$ & 6 & $\begin{array}{l}18, \\
2 \%\end{array}$ & 4 & $\begin{array}{l}12, \\
1 \%\end{array}$ & - & - & - & - \\
\hline & Prosedural & - & - & - & - & 15 & $\begin{array}{l}45, \\
5 \%\end{array}$ & 5 & $\begin{array}{l}15 \\
1 \% \\
\end{array}$ & - & - & - & - \\
\hline & Metakognitif & - & & - & - & - & - & - & - & - & - & - & - \\
\hline \multirow{4}{*}{2013} & Faktual & - & - & 2 & $\begin{array}{l}4,5 \\
\%\end{array}$ & - & - & - & - & - & - & - & - \\
\hline & Konseptual & - & - & 2 & $\begin{array}{l}4,5 \\
\%\end{array}$ & 6 & $\begin{array}{l}13, \\
6 \%\end{array}$ & 2 & $\begin{array}{c}4,5 \\
\%\end{array}$ & - & - & - & - \\
\hline & Prosedural & - & - & - & - & 24 & $\begin{array}{l}54, \\
5 \%\end{array}$ & 8 & $\begin{array}{l}18, \\
2 \%\end{array}$ & - & - & - & - \\
\hline & Metakognitif & - & - & - & - & - & - & - & - & - & - & - & - \\
\hline
\end{tabular}


Soal untuk dimensi mengaplikasikan (C3)prosedural ditunjukkan pada soal perhitungan persen massa komposisi suatu alloy. Penggunaan rumusan konsep stoikiometri dengan pengerjaan yang bertahap merupakan dimensi proses kognitif mengaplikasikan dan penerapan perhitungan matematik dalam menyelesaikan soal kimia dikategorikan kedalam dimensi pengetahuan prosedural. Soal berdimensi kognitif mengaplikasikan (C3)konseptual ditunjukkan pada soal penentuan suatu jenis senyawa hidrat yang di paparkan tiga kemungkinan jenis senyawa tersebut. Pada soal ini siswa diminta menyarankan uji untuk menentukkan kandungan senyawa, maka siswa perlu mengaplikasikan konsep penelitian/fenomena atau teori untuk menentukkan uji yang paling efektif. Pola soal mengaplikasikan(C3)-mengimplementasikan yang ditunjukkan pada OSN ini yakni penerapan terhadap rumusan pengerjaan matematik, berkenaan subtitusi data terhadap data lain, dan mengaplikasikan-melaksanakan ditunjukkan pada penerapan prinsip-prinsip kimia seperti penulisan persamaan reaksi.

Komposisi terbanyak kedua yakni soal-soal berdimensi proses kognitif menganalisis. Dimensi ini melibatkan proses memecah materi menjadi bagian kecil (membedakan) dan menentukan hubungan antara setiap bagian tersebut (mengorganisasi) [9]. Beberapa soal diantaranya memerlukan proses identifikasi elemen-elemen atau situasi agar siswa dapat menentukan struktur yang koheren dan menyelesaikan masalah, kategori ini yang disebut dengan mengorganisasi. Soal berdimensi menganalisis (C4)-prosedural ditunjukkan pada soal perhitungan konsentrasi awal senyawa dengan prinsip kesetimbangan kimia. Analisis dilakukan pada pengorganisasian data senyawa tersebut agar dapat disusun langkah prosedural yang tepat guna menyelesaikan masalah tersebut. Soal berdimensi kognitif menganalisis (C4)-konseptual ditunjukkan pada soal dengan materi subtitusi benzena, dalam hal ini perlunya analisis terhadap subtituen yang terkandung di dalamnya dan juga memerhatikan subtituen kedua yang akan masuk. Prinsip mengenai gugus prioritas pada materi ini merupakan pengetahuan konseptual.

Kategori dimensi kognitif memahami ini memiliki subkategori yang lain, yakni menafsirkan, mencontohkan, mengklasifikan, merangkum, dan menyimpulkan. Kebanyakan dari soal ini termasuk kategori menafsirkan yang menuntut siswa untuk pengubahan dari grafik menjadi tulisan, atau dari tulisan menjadi sebuah bahasa simbol. Soal berdimensi memahami (C2)-faktual di tunjukkan pada soal dengan materi kimia inti. Dikelompokkan ke dalam dimensi ini, karena soal telah menyebutkan nama unsur yang bereaksi, sehingga siswa hanya perlu menuliskan lambang simbol dari unsur tersebut tetapi juga perlunya memahami prinsip persamaan reaksi pada kimia inti yakni jumlah massa atom dan jumlah proton pada reaktan dengan produk haruslah sama, sehingga persamaan reaksi dapat dituliskan secara setara. Soal berdimensi mehamami (C2)-konseptual ditunjukkan pada soal materi energi pengaktifan. Pada soal disajikan persamaan reaksi yang diminta untuk diubah ke dalam bentuk grafik.

Pengetahuan prosedural menjadi dimensi paling dominan karena kebanyakan dari soal-soal olimpiade tersebut menuntut siswa menyelesaikan masalah dengan menggunakan perhitungan matematik dalam kuantitatif kimia [11]. Menurut hasil penelitian yang dikemukakan oleh Eisankraft dan Kotlicki [6], menyatakan kebanyakan soal olimpiade, khususnya bidang fisika $(I P h O)$ berkaitan dengan fungsi trigonometri yang merupakan perhitungan matematik, dan hal ini pun ini terlihat pada hasil analisis soal olimpiade bidang kimia, yang menjadi satu rumpun dengan fisika (IPA). Kondisi ini dipengaruhi silabus dari olimpiade tersendiri. Ciri-ciri pengetahuan prosedural dalam kimia terdiri dari kemampuan dalam praktikum, investigasi metode kimia dan operasi matematik dalam kuantitatif kimia, tetapi dalam soal-soal ini pengetahuan prosedural hanya dtunjukkan pada terdapat pada keterampilan dalam algoritme saja. Pola soal pada pengetahuan prosedural ditunjukkan pada pengetahuan tentang klasifikasi kategori dan pengetahuan mengenai prinsip generalisasi, sedangkan untuk pengetahuan mengenai teori, model dan struktur yang mecakup berbagai paradigm, epistemologi, teori dan model untuk mendeskripsikan suatu fenomena tidak banyak dimunculkan. Hubungan antara disiplin ilmu kimia dengan suatu fenomena hanya terdapat pada beberapa soal saja dan hal ini menjadi salah satu kelemahan dari soal OSN.

Dimensi paling banyak ditempati oleh mengaplikasikan. Kondisi ini dapat dijelaskan oleh silabus OSN yang kebanyakan berisikan materi-materi berkarakteristik konsep prinsip atau menyatakan simbol atau ukuran atribut, sehingga soal yang muncul lebih berkaitan dengan prosedural perhitungan kimia. Tujuan dari pemberian soal penerapan dengan jumlah yang banyak bisa saja dikarenakan kognitif mengaplikasikan lebih menuntut siswa untuk berpikir dan terbiasa menyelesaikan soal dengan tahapan (pengetahuan prosedural) dan pemilihan rumusan kimia (Higher-Order Cognitive Skills), dibandingkan hanya meretensi konsep kimia (Lower-Order Cognitive Skills). Kelemahan pada soal ini tidak ditemukannya kognitif mengevaluasi dan mencipta dan pengetahuan metakognitif. Dimensi pengetahuan ini lebih berhubungan dengan kemampuan psikomotor seperti pada kerja praktik.

Pengelompokkan terhadap dimensi ini berdasarkan tahapan penyelesaian soal yang dilakukan, walaupun kompleksitas kognitif sebenarnya dipengaruhi oleh kondisi siswa ketika menjawab soal [11], tetapi penelitian ini tidak dapat mencakup hingga keadaan tersebut. Perbandingan pada soal OSN dan IChO dilakukan pada empat materi yang sama, yakni kesetimbangan kimia, termodinamika, stoikiometri dan senyawa organik. Jenis soal yang digunakan pada keduanya sama, yakni menggunakan uraian objektif dengan pemberian wacana yang berhubungan dengan konten materi. Dimensi proses kognitif pada keduanya berada pada cakupan mengaplikasikan (C3)-menganalisis 
(C4). Dimensi pengetahuan pada keduanya yakni pengetahuan prosedural.

Konten materi yang diberikan pada $I C h O$ lebih luas dibandingkan dengan soal OSN. Hasil analisis menunjukkan bahwa cara penyajian konten materi pada satu soal IChO memiliki keterhubungan dari satu materi dengan materi yang lain. Contohnya, pada soal kesetimbangan kimia, diberikan data mengenai absorbansi senyawa yang terlibat dalam kesetimbangan, pertanyaan yang diajukan ialah konsentrasi dari senyawa tersebut, dalam hal ini terlihat adanya hubungan yang dibentuk dari dua materi kimia dalam penyelesaian satu soal.

Pada analisis wacana untuk kedua olimpiade dengan materi yang sama menunjukkan pada materi kesetimbangan kimia, termokimia, laju reaksi, ikatan kimia, dihadirkan kasus soal dengan cakupan masalah yang berhubungan dengan penerapan dalam kehidupan seharihari dan penjelasan keberadaan alam menggunakkan ilmu kimia. Berbeda pada materi reaksi redoks dan sistem periodik unsur, pada soal IChO seperti halnya wacana dengan contoh kasus untuk dijelaskan, tetapi pada soal OSN terdapat wacana yang merupakan pengertian dari konsep tersebut. Hal ini menunjukkan suatu kelemahan soal olimpiade sains nasional yang terdapat di Indonesia. Seperti yang dijelaskan dalam pedoman penulisan soal uraian [12], stimulus yang terdapat pada soal merupakan contoh kasus, grafik, tabel, dll, tetapi pengertian dari konsep merupakan suatu wacana yang tidak diperlukan.

Perbedaan yang terjadi pada soal kedua jenis olimpiade ini dikarenakan silabus keduanya yang memiliki perbedaan. Terlebih untuk olimpiade-olimpiade internasional, konten materi soal yang muncul juga disesuaikan dengan karakteristik negara tempat penyelenggaraan kegiatan tersebut.

Hasil penyebaran menunjukkan hampir dari setengah soal OSN pada tahun 2012 dan 2013 tidak memiliki kompetensi dasar yang sesuai. Hal ini terjadi karena konten materi soal olimpiade lebih tinggi dibandingkan dengan jenjang sederajatnya.
Arah olimpiade memiliki silabus tersendiri dan juga kurikulum pendidikan di Indonesia bertujuan pada ujian nasional bukan pada ajang olimpiade semacam ini, kurikulum pun disesuaikan dengan keberagaman kondisi masyarakat di Indonesia serta pemerataan pendidikan yang belum berhasil, sehingga pendidikan formal di sekolah nampaknya tidak cukup untuk menghantarkan siswa ke ajang seperti OSN dan IChO, maka guru baiknya dapat memberikan kedalaman materi dalam setiap pembelajaran beserta latihan soal sejenis soal olimpiade atau siswa mendapatkan pembelajaran tambahan selain di sekolah guna meraih kompetisi ini.

Berbeda dengan pemetaan ujian nasional yang telah memiliki standar kelulusan sehingga soal yang disajikan akan sesuai dengan standar kompetensi dan kompetensi dasar yang telah ditetapkan, sehingga perbedaan konten materi pun jelas terlihat pada kedua jenis soal ini. Menurut penelitian yang dilakukan oleh Satrisman [4] menunjukkan analisis terhadap soal ujian nasional, terdapat satu kompetensi dasar tercantum pada SKL yang tidak memiliki perwakilan soal, penyebaran soal tersebut pada dimensi proses kognitf yakni pada mengingat, memahami, mengaplikasikan, dan menganalisis dengan persentase terbesar pada level C1-C3.

Pada soal ujian nasional kimia tahun 2013 menunjukkan kebanyakan soal memenuhi pengetahuan konseptual [4], sedangkan soal olimpiade ini memenuhi pengetahuan prosedural. Perbedaan yang terjadi dapat dikembalikan pada tujuan adanya kedua program ini sendiri, jika ujian nasional sebagai bentuk evaluasi yang mengukur tingkat keberhasilan siswa sesuai dengan kompetensi dasar yang telah dicantumkan oleh pemerintah, sedangkan olimpiade sains nasional diselenggarakan guna menjaring dan memfasilitasi siswa-siswa yang memiliki kemampuan lebih tinggi dibandingkan siswa lainnya atau berfungsi menjaring siswa-siswa berprestasi, sehingga soal yang disajikan dari kedunya pun berbeda dengan cukup signifikan.

Manfaat dari analisis soal ini dapat memberikan gambaran tipe, konten materi dan ranah kognitif yang

Tabel. 3 Penyebaran Soal-soal OSN Bidang Kimia pada SK-KD SMA/MA

\begin{tabular}{|c|c|c|c|c|}
\hline $\begin{array}{l}\text { Jenjang } \\
\text { Kelas }\end{array}$ & $\begin{array}{c}\text { Standar } \\
\text { Kompetensi }\end{array}$ & $\begin{array}{c}\text { Kompetensi } \\
\text { Dasar }\end{array}$ & Jumlah Soal & Persentase \\
\hline \multirow[t]{3}{*}{$\mathrm{X}$} & \multirow[t]{2}{*}{2} & 2.1 & 6 & $7,8 \%$ \\
\hline & & 2.2 & 4 & $9,1 \%$ \\
\hline & 3 & 3.2 & 3 & $3,9 \%$ \\
\hline \multirow[t]{7}{*}{$\mathrm{XI}$} & \multirow[t]{3}{*}{1} & 1.1 & 4 & $5,2 \%$ \\
\hline & & 1.2 & 6 & $7,8 \%$ \\
\hline & & 1.3 & 1 & $1,3 \%$ \\
\hline & 2 & 2.2 & 1 & $1,3 \%$ \\
\hline & \multirow[t]{2}{*}{3} & 3.2 & 1 & $1,3 \%$ \\
\hline & & 3.4 & 4 & $5,2 \%$ \\
\hline & 4 & 4.1 & 5 & $6,5 \%$ \\
\hline XII & 4 & 4.1 & 1 & $1,3 \%$ \\
\hline \multicolumn{3}{|c|}{ Jumlah Keseluruhan } & 40 & $50,7 \%$ \\
\hline
\end{tabular}


terkandung dalam soal-soal olimpiade sains nasional khususnya pada bidang kimia dan juga memberikan masukan kepada guru untuk mengetahui kedalaman konten soal yang diujikan pada olimpiade sains nasional, agar guru mengetahui tingkat kedalaman materi pembelajaran yang harus di berikan kepada para siswa tertentu yang akan mengikuti ajang kompetisi ini.

\section{KESIMPULAN DANSARAN}

\section{Kesimpulan}

Hasil analisis menunjukkan bahwa soal-soal OSN pada tahun 2012 dan 2013 untuk bidang kimia memiliki persentase terbesar yakni pada dimensi kognitif mengaplikasikan (C3) dan pengetahun prosedural. Persamaan OSN dan $I C h O$ terdapat pada dimensi yang digunakan, sedangkan perbedaannya pada tingkat kedalaman konten materi soal yang diujikan. Soal ini dapat dipetakan terhadap SK-KD SMA/MA Kimia sebesar 50,7\% dari jumlah keseluruhan yakni sebanyak 77 soal.

\section{Saran}

Kekosongan pada level kognitif mengevaluasi dan mencipta dapat ditambahkan dengan mengubah pola soal seperti, adanya gambar sebagai stimulus agar siswa lebih menganalisis kondisi, keterhubungan antara fenomena alam dengan materi kimia lebih dibangun agar siswa mampu merancang percobaan penyelesaian masalah, dan lainnya. Soal $I C h O$ memiliki konten materi yang lebih luas dibandingkan dengan OSN, maka sebaiknya soal dapat dibuat dengan mengacu pada kecenderungan konten materi yang terdapat pada IChO . Bagi para guru, baiknya perkuat konsep yang diberikan kepada siswa agar bentuk soal semacam olimpiade atau lainnya mampu diselesaikan oleh siswa dan mulai mengenalkan tipe soal OSN pada latihan soal dalam pembelajaran, sebagai bentuk pengembangan soal agar lebih menggali kemampuan siswa sehingga mampu bersaing di dunia internasional.

\section{Ucapan terima kasih}

Penulis mengucapkan terima kasih kepada Dekan Fakultas Tarbiyah dan Keguruan, Ketua Jurusan Pendidikan MIPA, dan Ketua Prodi Pendidikan Kimia, UIN Bandung atas kesempatan yang diberikan pada keikutsertaan dalam penulisan karya ilmiah ini. Penulis juga berterima kasih kepada Dr. Yunita, M.Pd. dan Euis Nursa'adah, M.Pd. atas bimbingannya dalam penelitian ini.

\section{Daftar Rujukan}

[1] BSNP. (2006). Standar Isi Mata Pelajaran Kimia SMA/ MA. Jakarta : Departemen Pendidikan Nasional

[2] Atjenon. (2007). Good, bad Assessment. Jyvaskyla: Gummerus Kirjapaino Oy, 19-170

[3] Tsaparlis dan Zoller. (2003). Evaluation of higher vs. lower-order cognitive skills-type examinations in chemistry: implications for university-class assessment and examinations. University Chemistry Education, 7(2), 50-57

[4] Satrisman, Adi. (2013). Analisis Soal Ujian Nasional Kimia SMA Tahun 2013 Berdasarkan Taksonomi Bloom Dua Dimensi. Skripsi. Bandung : UPI. Tidak diterbitkan

[5] Tikkanen, Greta. dan Aksela, Maija. (2012). Analysis of Finnish chemistry Matriculation Examination questions according to Cognitive Complexy. Journals of uio. 8, (3), 258-286

[6] Eisenkraft, Arthur. Kotlicki, Andrezej. (2010). Theoretical and Experimental Problems of The International Physics Olympiad-Requirements and Priorities. Norwegian University of Science and Technology. [Online]. Tersedia:http://ipho.phy.ntnu.edu.tw/news/ FINAL(Kotlicki).pdf. [Diakses 2 Juni 2014]

[7] Jabubowski, M. (2013). Analysis of the Predictive Power of PISA Test Items. OECD Education Working Papers, (87).

[8] Herron, J. Dudley., et.al. (2010). Problems Associated With Concept Analysis. Journal of Science Education, 61,(2), 185-199

[9] Anderson, Lorin W dan Krathwohl, David R, (Eds). (2001). Kerangka Landasan Untuk Pembelajaran, Pengajaran dan Asesmen. Terjemahan oleh Agung Prihantoro. Yogyakarta : Pustaka Pelajar.

[10] Gunawan, Imam dan Palupi. (2012). Taksonomi Bloom-Revisi Ranah Kognitif Kerangka Landasan Untuk Pembelajaran, Pengajaran dan Penilaian. [Online].Tersedia,http:// www.ikippgrimadiun.ac.id/ejournal/sites/ default/files.pdf. [Diakses 27 September 2013]

[11] Krathwohl, D. R. (2002). A revision of Bloom's taxonomy: An overview. Theory into Practice, 41,(4),212-218.

[12] Depdiknas. (2003). Penialaian Tingkat Kelas. Jakarta : Departemen Pendidikan Nasional 